\title{
Parallel Modeling Approach to Assess Morphological Impacts of Offshore Sand Extraction
}

\author{
Saskia Hommes ${ }^{\dagger}$, Suzanne J.M.H. Hulscher ${ }^{\dagger}$, and Ad Stolk \\ University of Twente \\ Faculty of Engineering Technology \\ Department of Water Engineering and \\ Management \\ P.O. Box 217 \\ 7500 AE Enschede \\ The Netherlands \\ s.hommes@utwente.nl \\ Ministry of Transport, Public Works and \\ Water Management \\ North Sea Directorate \\ P.O. Box 5807 \\ 2280 HV Rijswijk \\ The Netherlands
}

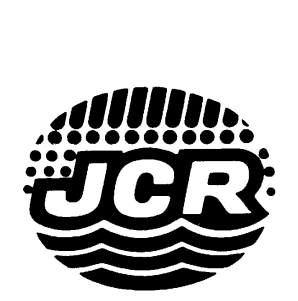

\begin{abstract}
HOMMES, S.; HULSCHER, S.J.M.H., and STOLK, A., 2007. Parallel modeling approach to assess morphological impacts of offshore sand extraction. Journal of Coastal Research, 23(6), 1565-1579. West Palm Beach (Florida), ISSN
\end{abstract} 0749-0208.

\begin{abstract}
In this paper, we focus on a complex management issue, namely the physical effects of a large-scale offshore sand extraction. For these kinds of issues there is no obvious morphological model available to answer all management questions. Therefore, we aim to answer as many management questions as possible, using a set of existing morphological models parallel to each other. In this way, we can support governments to assess applications for licenses for large-scale sand extraction. We investigate whether this parallel modeling approach is significantly more helpful in addressing the management questions than a single modeling approach. The management questions are translated into quantifiable variables, known as Coastal State Indicators (CSIs). We focus on three coastal user functions: coastal safety and maintenance, offshore infrastructure, and navigation. The selected morphological models are assessed on (1) their applicability to the CSIs and (2) the reliability of their predictions. We quantify the predictive power of the models based on these two parameters. We conclude that by using a parallel modeling approach it is possible to address more management questions effectively in comparison with using just the best single model. The use of this parallel modeling approach increases the predictive power significantly, here $35 \%$.
\end{abstract}

ADDITIONAL INDEX WORDS: Management questions, coastal user functions, coastal state indicator (CSI), sand ridges, predictive power.

\section{INTRODUCTION}

The North Sea is a relatively small shelf sea compared with oceans; nevertheless it is teeming with life. Water and sediment are home to a wide variety of species. The North Sea is also a sensitive ecosystem that is under much pressure from intensive human activities such as fishing, sand and gravel extraction, shipping, oil and gas extraction, tourism, and industry. On the Netherlands Continental Shelf, an average of $30 \times 10^{6} \mathrm{~m}^{3}$ of sand is extracted every year to be used as fill sand, for coastal protection, and for large infrastructural projects. In the near future, land reclamation projects and sand extraction for the construction industry may lead to larger and deeper sandpits and sand extraction from ridges. In the Dutch regulations it is determined that for a large-scale extraction an Environmental Impact Assessment (EIA) must be executed before extraction licenses can be granted. Thus, authorities and initiators need information on

DOI: 10.2112/06-0698.1 received 2 May 2006; accepted in revision 18 January 2007.

This project is supported by Technology Foundation STW, the applied science division of NWO and the technology program of the Ministry of Economic Affairs in the Netherlands. the environmental impacts of a proposed sand extraction for these licenses.

Several studies related to the behavior of sand extraction pits in the North Sea have been done recently and are still ongoing. HoOGEwONING and BoERs (2001) give an outline of the most important physical effects of offshore sand extraction, specifically the influence on flow, sediment transport, and morphology. Furthermore, they relate these physical effects to user functions. VAN RIJN and WALSTRA (2002) evaluate and summarize studies that focus on the flow and morphology of extraction pits in the North Sea using two- and three-dimensional hydrodynamic and morphodynamic models and also bed instability models (VAN RIJN and WALSTRA, 2002). Furthermore, the PUTMOR project, a measuring campaign on a temporary deep sand pit near the Dutch coast, provides hydrodynamic and morphological field data (BOERs, 2005). Finally, Roos (2004) gives an extensive literature review on morphodynamic effects of offshore sand extraction.

In this paper, we use the Zeeland ridges, a group of sand ridges offshore of the Netherlands, as a reference study area. In this area, no large scale sand extraction has been executed yet. However, it is an interesting location for future sand extraction because there is a large amount of sand available. Furthermore, it is close to the coast, which is positive for 


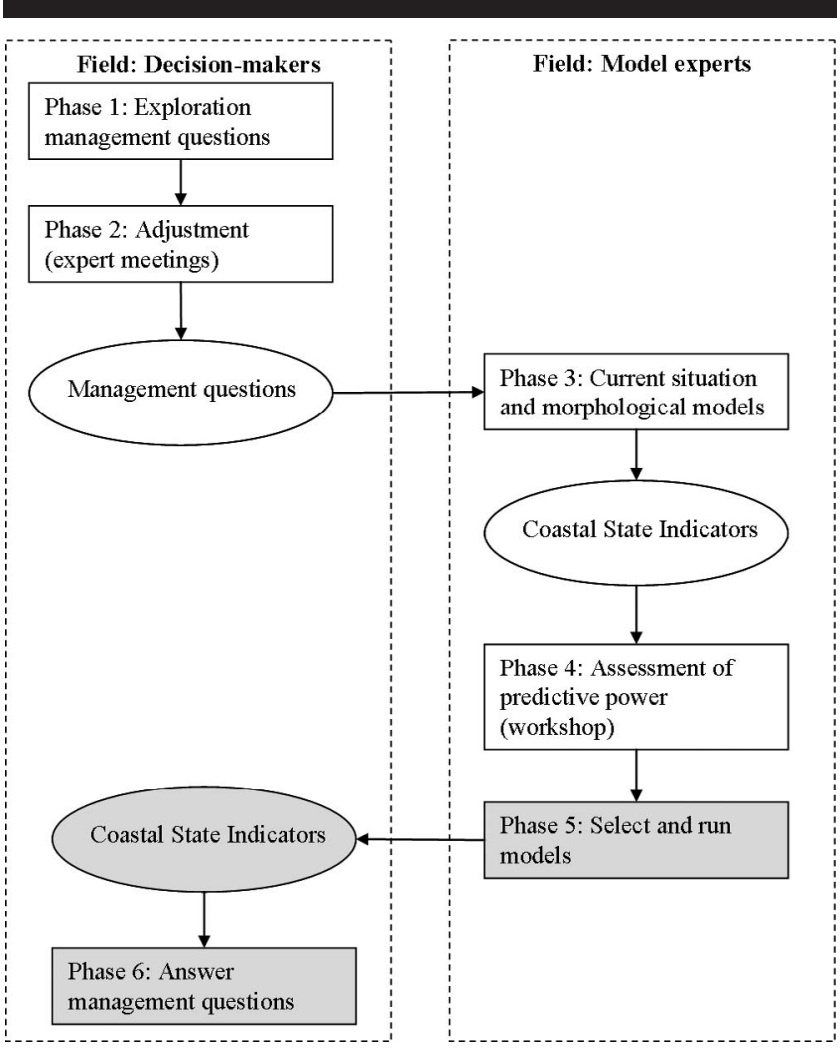

Figure 1. Approach for formulating and answering management questions on offshore sand extraction (adapted after: Van Koningsveld et al., 2005). The gray blocks were not included for the reference study area of the Zeeland ridges.

economic reasons (i.e., navigation distance is small). On the other hand, it is an ecologically interesting area where other activities also take place. We concentrate on management issues regarding the long-term (up to 100 years) physical effects of such a sand extraction. Although, we use a Dutch case as a reference study area, the method presented in this paper can also be applied to other areas throughout the world where similar issues are at stake, for example, in the United States (e.g., BYRnEs et al., 2004a, 2004b; DRUCKER, WASKES, and ByRnes, 2004; Kelley, RAMSEY, and ByRNES, 2004; MAA et al., 2004), United Kingdom (e.g., HiтchCOCK and Bell, 2004; Singleton, 2001), Australia and New Zealand (e.g., Hilton and Hesp, 1996; Pattiaratchi and Harris, 2002), and Japan (e.g., TsurusakI, IwASAKI, and ARITA, 1988; YoshidA and TAKASUGI, 2005).

Our objective is to address as many management questions focusing on morphological impacts of sand extraction as possible at this moment using existing morphological models parallel to each other. This way the decision-making process on granting licenses for sand extraction can be supported. We investigate whether this parallel modeling approach is significantly more helpful in addressing the management questions than a single modeling approach. In this paper, we focus on the information needs of stakeholders (management questions) regarding a large scale sand extraction on the Zeeland

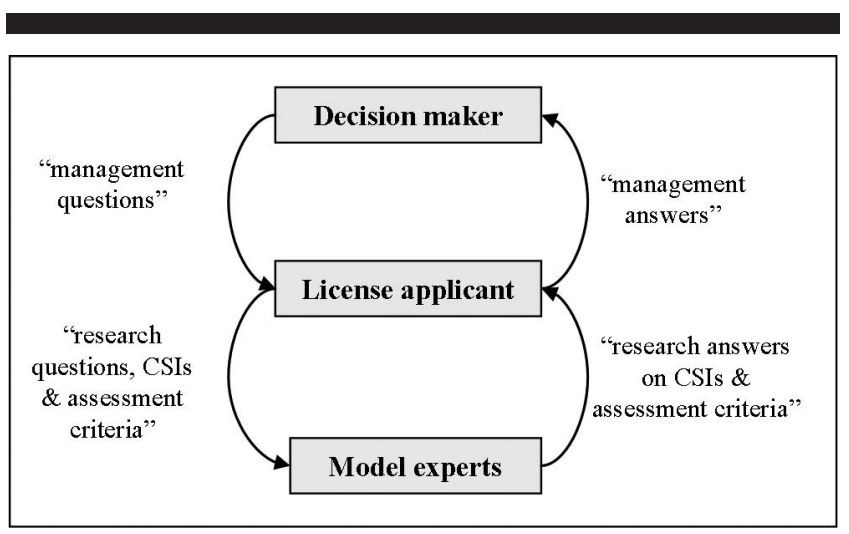

Figure 2. Process information chain.

ridges. We used the approach that is shown in Figure 1. In the first phase, the management questions are explored by interviews with decision makers. Also, the basic assumptions, the information users, and the process information chain (Figure 2) were explored. In the second phase, the outcomes of the first phase were adjusted in meetings with four morphological experts (from National Institute of Coastal and Marine Science/RIKZ, University of Twente, and DirectorateGeneral of Public Works and Water Management/RWS). At the end of the second phase, the information needs of the coastal managers are specified in management questions. In the third phase, the current situation of the reference study area is investigated (next section). Furthermore, an important aid in addressing the management questions using morphological models is to define so-called Coastal State Indicators (CSIs). These indicators are well-defined physical variables quantifying a socioeconomic functional use of the coastal zone. Each indicator is related to a specific coastal user function. In this paper, we focus on three coastal user functions: coastal safety and maintenance, offshore infrastructure, and navigation (see "Coastal State Indicators" section).

Next in the third phase, a concept inventory of morphological models is formulated and the morphological models are explored. We include state-of-the-art morphological models, idealized process-based models, and full process-based models in this study (see "Morphological Models of the Impact of Sand Extraction" section). In the fourth phase, the morphological models are assessed; this was accomplished by the organization of a workshop for model experts (HoMMEs, 2004b) and a method to characterize the predictive power of these morphological models on the CSIs. This method distinguishes between the applicability of the models and the reliability of their predictions. The results of this workshop and the predictive power method are used to determine in the final inventory of morphological models (see "Predictive Power of Morphological Models" section). Subsequently, the sensitivity of the results to the definition of the predictive power and to the use of the parameters of applicability and reliability is tested (see "Sensitivity Analysis" section). Finally, in the last two sections of the paper, the results are discussed and conclusions are drawn. 


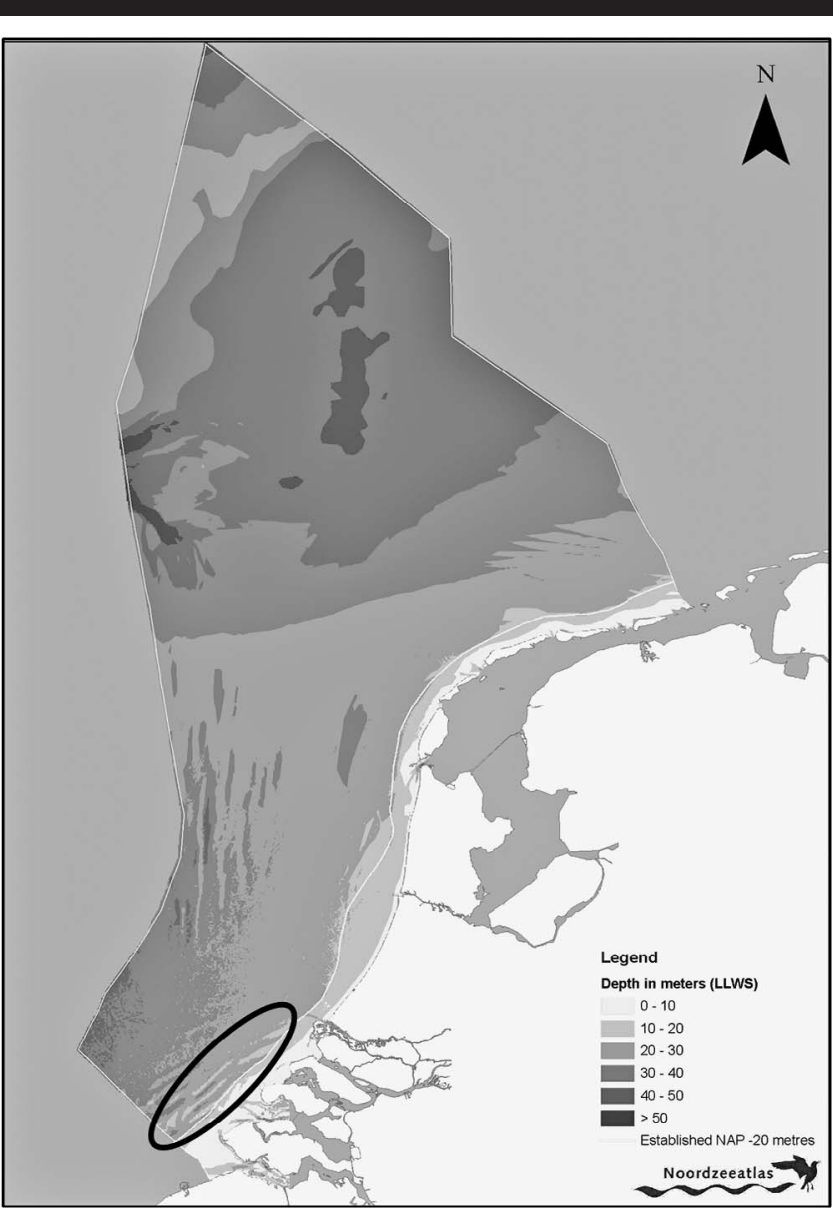

Figure 3. Water depth (meters compared to LLWS) Netherlands Continental Shelf with Zeeland ridges, study area in this paper, marked in the circle (Noordzeeatlas, 2005).

\section{REFERENCE STUDY AREA: THE ZEELAND RIDGES}

\section{Physical Description}

The Zeeland ridges make up a group of ridges located in front of the coast (7.5-11.5 km offshore) of the Dutch provinces of Zeeland and Zuid-Holland, seaward from the established $-20 \mathrm{~m}$ NAP depth contour line (Figure 3 ). The characteristics of the Zeeland ridges are: 5-15 $\mathrm{m}$ in height, 9-39 $\mathrm{km}$ in length, $3-7 \mathrm{~km}$ transverse spacing, oriented $0^{\circ}-20^{\circ}$ clockwise with respect to the tide, partly covered with sand waves of 2-8 $\mathrm{m}$ in height. The origin and classification of the Zeeland ridges is not clear. The Zeeland ridges are similarly oriented as shoreface-connected ridges, but they are clearly not connected to the shore. Also, the ridges could be classified as offshore tidal sand ridges. However, their orientation is mirrored as would be expected for tidal sand ridges in general. Therefore, no clear conclusion can be drawn yet on the classification of the Zeeland ridges.

The North Sea is a tidally dominated shelf sea. The typical tidal range in the North Sea varies from 0 to $6.5 \mathrm{~m}$. In the area of the Zeeland ridges, the typical tidal range varies, from south to north, from 3.5 to $2.5 \mathrm{~m}$. At a spring tide the tidal range is around $4.5 \mathrm{~m}$ and at a neap tide it is around $2.5 \mathrm{~m}$ (Het GetiJ, 2005). The strength of the tidal currents in the North Sea is generally moderate, and in the area of the Zeeland ridges it is around $0.75 \mathrm{~m} / \mathrm{s}$ (NoORDZEEATLAS, 2005). In general, wind can increase or decrease the rates of tidal currents depending on the directions of the wind and currents. The wave climate is rather uniform along the Dutch coast: the dominant wave direction is southwest. Some values of the probability of occurrence (duration in percent of time) for waves in deep water are:

- Southwest $\left(180^{\circ}-270^{\circ}\right): 15 \%$ waves of $1-2 \mathrm{~m}, 4 \%-5 \%$ between $2-3 \mathrm{~m}, 1 \%-2 \%$ between $3-5 \mathrm{~m}$

- Northwest $\left(270^{\circ}-360^{\circ}\right): 10 \%$ waves of $1-2 \mathrm{~m}, 4 \%-5 \%$ between $2-3 \mathrm{~m}, 1 \%-2 \%$ between $3-5 \mathrm{~m}$.

The wave heights mentioned are significant wave heights (VAN RIJN and WALSTRA, 2002).

An essential aspect of a coastal system, like the area of the Zeeland ridges, is that currents and waves are capable of transporting water and sediment. For the area of the Zeeland ridges, no measurements of sediment transport are available. So as an alternative, we investigate the sediment transport on the Belgian and Netherlands Continental Shelf from literature reports, and it appears that the average longshore total transport rate is about $10-100 \mathrm{~m}^{3} / \mathrm{m} / \mathrm{yr}$ at a depth of 10-20 m. However, the transport on the top of a ridge can be much higher, at about $200 \mathrm{~m}^{3} / \mathrm{m} / \mathrm{yr}$ (KLEINHANS, 2002; LANCKNEUs et al., 2001; VAN RIJN and WALSTRA, 2002; VINCent, Stolk, and Porter, 1998; WL Delft Hydraulics, 2003). We assume that the transport rate in the area of the Zeeland ridges will be lower because they lie at a depth of 20-30 m. These transport rates will probably change after large-scale extraction has taken place. It is difficult to determine the exact transport rates after large-scale extraction from a ridge because there is very little experience with such large-scale interventions. The recovery period of a dredged ridge, a temporal scale of adjustment to changes in environmental conditions, is probably on the order of decades to centuries depending on the volume and geometry of the pit (Roos, 2004; Van de Meene, 1994).

\section{Coastal User Functions}

The area of the Zeeland ridges is used for various functions (see Figure 4). A pipeline crosses the southern part of the seabed. Furthermore, there are many cables (both in and out of use) running through the central part of the Zeeland ridges area. There are also some parts of the ridges on which smallscale extractions have taken place already. Moreover, shipping routes and an anchor area are located around and on the Zeeland ridges. Finally, the proximity of the ridges to the coastline and the shallowness of the area make them unique from an ecological point of view. The continuous interaction between the morpho- and hydrodynamics of the sand ridge system generates a variety of habitats (DEwICKE et al., 2003). DEWICKE et al. (2003) distinguished two gradients in ecosystem structure on the Zeeland ridges (and Belgian ridges): the onshore-offshore gradient perpendicular to the coastline, indicating differences in density and biomass, and the east- 


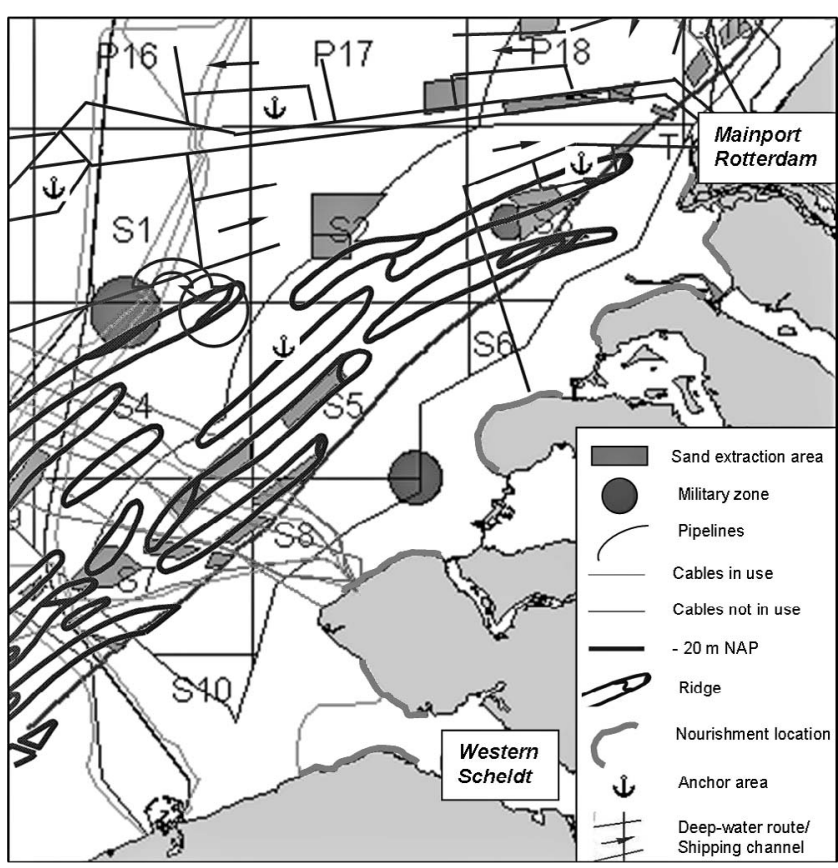

Figure 4. User functions in the area of the Zeeland ridges (map from RWS, DNZ, 2003).

west gradient along the coastline, reflecting species richness and diversity. VANAVERBEKE et al. (2002) also distinguish these two gradients, but also a third gradient, which reflects differences between troughs and crests of the ridges. Although these ecological aspects are of importance for the area, as indicated in the previous discussion, this user function is not taken into account in this paper. We restrict ourselves to considering the user functions coastal safety and maintenance, offshore infrastructure, and navigation.

The coastal safety and maintenance user function focuses on the nearshore area, in this case the Dutch coast. This function deals with the prevention of flooding and the maintenance of the coastline. The Dutch government Ministry of Transport, Public Works and Water Management is responsible for these aspects. Offshore infrastructure includes cables, pipelines, and offshore structures, such as oil platforms and wind turbine parks. The main point of concern for this user function is the maintenance of the offshore infrastructure. The Dutch government, that is, the Ministry of Economic Affairs; Ministry of Transport, Public Works and Water Management; and Ministry of Housing, Spatial Planning and the Environment, are the authorities in this matter.

Mainport Rotterdam (The Netherlands), one of the largest ports of the world, is located just northeast of the reference study area. Also the Western Scheldt, located southwest of the Zeeland ridges, is used for navigational purposes. This estuary connects with the river Scheldt, which leads to the port of Antwerp (Belgium) and the Channel of Gent to Terneuzen, leading to the port of Gent (Belgium). These three ports generate much navigational traffic on the North Sea, which moves through deepwater routes and shipping chan- nels. Furthermore, vessels approaching the ports often have to wait for their pilot service. Therefore, anchor areas have been established, two of which are located in the area of the Zeeland ridges, functioning as a waiting room. These routes, channels, and anchor areas prevent conflicts between navigation and other user functions. The main point of concern for navigation regarding the long-term effects of large-scale sand extraction is safety (VAN WOERDEN, 2002) because changes in water depths and currents may affect the shipping routes in the reference study area and the anchor areas, which are located on two of the Zeeland ridges.

\section{Regulations on Offshore Sand Extraction in the Netherlands}

The regulations governing sand extraction in the Dutch North Sea are set out in the Regional Extraction Plan North Sea, RON/MER (Regionaal Ontgrondingenplan Noordzee [in Dutch]). The most important statements in RON/MER are: sand extraction is only allowed seaward from the $-20 \mathrm{~m}$ NAP depth contour line, except for harbor entrances and shipping channels; only deepening up to $2 \mathrm{~m}$ is allowed; and an area that has been extracted once is not allowed to be extracted again. The minimum distance from an extraction pit to offshore infrastructure (cables, pipelines, and offshore structures) is $500 \mathrm{~m}$, with a pit depth of $2 \mathrm{~m}$.

The RON/MER was updated, resulting in the second Regional Extraction Plan North Sea (RON2). RON2 differs from RON/MER on the following points: it distinguishes between small-scale extraction $\left(<10 \times 10^{6} \mathrm{~m}^{3}\right)$ and large-scale extraction $\left(>10 \times 10^{6} \mathrm{~m}^{3}\right)$; for large-scale extraction or extraction of an area greater than 500 hectares, an EIA is required; the $-20-\mathrm{m}$ NAP depth contour line as landward boundary for extraction is replaced by the established -20 $\mathrm{m}$ NAP depth contour line; for large-scale extraction, it is possible to mine deeper than $2 \mathrm{~m}$, if an EIA shows that this is acceptable (RIJKswAterstaAt, 2004; STOLK, 2003). The Dutch government is the official authority that grants extraction licenses.

\section{COASTAL STATE INDICATORS}

\section{Coastal Zone Management}

From a Coastal Zone Management (CZM) perspective, the context of sand extraction is determined by the physical context (that is, the physical and ecological environment); the socioeconomic context (that is, socioeconomic functional uses of the coastal zone), and the administrative context (that is, the institutional arrangements, regulations, legislation, and directives). CZM will be based on an integrated analysis of this context. A coastal manager will aim for a rational decision-making process that is both transparent and reproducible. The (vague) strategic CZM objectives need to be translated into (specific) operational objectives (VAN RIJN et al., 2005). An important aid in this process is the definition of a set of CSIs: "a reduced set of issue-related parameters that can simply, adequately and quantitatively describe the dynamic-state and evolutionary trends of a coastal system" (Van Koningsveld, Davidson, and Huntley, 2005; Van 
RIJN et al., 2005). Each indicator is related to a specific coastal user function.

\section{Coastal State Indicators for the Zeeland Ridges}

In Table 1, we set out management and research questions, CSIs, and assessment criteria for each of the three selected coastal user functions for the reference study area of the Zeeland ridges. These research questions are formulated through personal communication with decision makers (coastal managers) and model experts, as is shown in the process information chain (Figure 2). The decision makers provided management questions (main questions 1 to 6 in Table 1) related to sand extraction on the Zeeland ridges in several in-depth interviews. These questions were translated into research questions (subquestions 1.1 to 6.3 in Table 1), CSIs, and assessment criteria by the authors in cooperation with model experts of the morphological models that are included in this paper. The model experts were interviewed and participated in a workshop that was organized at the National Institute of Marine and Coastal Science (RIKZ, The Hague, The Netherlands) in November 2003 (see Hommes, 2004b). Our approach to formulate CSIs is comparable with the approach used by VAN Koningsveld, DAvidson, and Huntley (2005). Note that not all assessment criteria are yet determined and/or quantified; should this method be used for a sand extraction application, this should be encountered. Furthermore, the list given in Table 1 is not exhaustive. However, the list does represent many important issues regarding the management of large-scale sand extraction and is therefore sufficient.

\section{MORPHOLOGICAL MODELS OF THE IMPACT OF SAND EXTRACTION}

The authors selected a series of morphological models to be analyzed based on expert judgment. In this paper, we focus on three classes of morphological models:

- Idealized process-based models, which take into account processes relevant on the scale of interest,

- Full process-based models, which are based on the description of small-scale processes,

- Behavior-oriented models, which aim at describing the general behavior of a phenomenon without going into the details of the underlying physical processes.

\section{Idealized Process-Based Models}

\section{Twente Model}

The Twente model described by Roos and Hulscher (2003) is an extension to the class of simple offshore models that describe large-scale bed evolution in shallow shelf seas. In the Twente model, a shallow sea with a flat bed is considered in which a tidal wave is active. The boundaries of the offshore system are taken infinitely far away (Figure 5). The morphodynamic model consists of a set of linearized equations that describe the interaction between tidal flow, sediment, and the sea bed. We consider a tidal flow that is a generalization of the $\mathrm{M}_{2}$-tide and add an $\mathrm{M}_{0}$-component (a residual current) along with an $\mathrm{M}_{4}$-component, thus allowing for tidal asymmetry. To model sand extraction using the Twente model, a sand pit can be seen as a superposition of wavy bed perturbations of small amplitude, which is represented in the problem as an initial bed profile (Roos et al., 2001). In Figure 6, the bed evolution of two extraction pits is shown. From this figure we find that an asymmetrical tide causes the pits to migrate, and they further turn out to extend themselves in a counterclockwise direction with respect to the main tidal axis. Additional humps appear next to and downstream of the pit, thus indicating that a pattern of banks may gradually appear around the pit. Note that the bed responses are qualitatively similar but differ with respect to the details. The migration rates, however, appear to be identical (Roos, 2004).

\section{Utrecht Model}

The Utrecht model (De Swart and Calvete, 2003; WaLGREen, Calvete, and De Swart, 2002) is an idealized morphodynamic model that can be used to gain an understanding about the formation and characteristics of shoreface-connected sand ridges and tidal sand ridges on the continental shelf. The shelf geometry is schematized as a semi-infinite domain, bounded on the landward side by the transition from the shoreface to the inner shelf. In the cross-shore direction it consists of an inner shelf (linearly sloping bottom) and an outer shelf represented by a horizontal bottom (Figure 7). A nonlinear variation of this morphodynamic model is used to study the response of shoreface-connected sand ridges and the net sand balance of the tidal coastal shelf to large-scale sand extraction.

Figure 8 shows a sand extraction (volume $=1.3 \mathrm{Mm}^{3}$ ) from a ridge. The results show that the response of the system is such that it returns to its original state. These findings agree, at least qualitatively, with field observations (BOERs, 2005; KNAAPEN and Hulscher, 2002; PATTIARATCHI and HARRIS, 2002). Thus, the system does not tend to a new equilibrium, which might have been expected in such a highly nonlinear system. An important implication of the response is that the inner shelf (where the ridge is located) must import sand. The results show that sand is transferred from both the nearshore zone and the outer shelf to the inner shelf, although the largest contribution is from the outer shelf (DE SWART and CALVETE, 2003).

\section{Full Process-Based Models}

\section{Delft3D}

Delft3D is a two- and three-dimensional integrated, spatially discretized full process-based model for the calculation of hydrodynamics, waves, sediment transport, bottom morphology, water quality, and ecology. Delft3D simulates the temporal and spatial variations of these six components and their interconnections. The model consists of a number of modules that are linked to and integrated with one another. The hydrodynamic, wave, and morphodynamic modules are used to model the physical effects of sand extraction (WL Delft Hydraulics, 2003). Between October 1999 and 
Table 1. Management questions (in italic) and research questions, coastal state indicators, and assessment criteria for the reference study area of the Zeeland ridges.

\begin{tabular}{|c|c|c|}
\hline Management and Research Questions & Coastal State Indicator (CSI) & Assessment Criteria \\
\hline \multicolumn{3}{|c|}{ Coastal safety and maintenance } \\
\hline $\begin{array}{l}\text { 1. Will a large-scale extraction pit act as a sediment } \\
\text { sink? }\end{array}$ & $\begin{array}{l}\text { Coastline position }\left(\mathrm{MCL}^{*}\right) \text { as a function of time }(50- \\
100 \mathrm{yr})\end{array}$ & Maintain MCL; $f(t)$ \\
\hline $\begin{array}{l}\text { 1.1 What impact will it have on nearshore sediment } \\
\text { transport regimes? }\end{array}$ & $\begin{array}{l}\text { Sand budget in the nearshore zone } \dagger \text { as a function of } \\
\text { time (50-100 yr) }\end{array}$ & Maintain sand budget; $f(t)$ \\
\hline \multicolumn{3}{|l|}{1.2 Will it lead to an increase in coastal erosion? } \\
\hline $\begin{array}{l}\text { 2. Will large-scale sand extraction in the area of the } \\
\text { Zeeland ridges affect the tidal flow and wave re- } \\
\text { gime? }\end{array}$ & $\begin{array}{l}\text { Erosion profile } \ddagger \text { (at times of a storm) as a function of } \\
\text { time (50-100 yr) }\end{array}$ & Minimum erosion profile; $f(t)$ \\
\hline $\begin{array}{l}2.1 \text { What is the effect of large-scale sand extraction } \\
\text { on the nearshore tidal currents? }\end{array}$ & $\begin{array}{l}\text { Coastline position (MCL) as a function of time (50- } \\
100 \mathrm{yr})\end{array}$ & Maintain MCL; $f(t)$ \\
\hline \multicolumn{3}{|l|}{$\begin{array}{l}2.2 \text { What is the effect of large-scale sand extraction } \\
\text { on the waves in the nearshore area? }\end{array}$} \\
\hline \multicolumn{3}{|c|}{ Offshore infrastructure } \\
\hline $\begin{array}{l}\text { 3. Will the extraction pit act as sediment sink and } \\
\text { thereby have a particularly marked impact on the } \\
\text { seabed in the area of the pit? }\end{array}$ & $\begin{array}{l}\text { Coverage of cables and free span of pipelines as a } \\
\text { function of time }(50-100 \mathrm{yr})\end{array}$ & $\begin{array}{l}\text { Minimum coverage of cables }=1 \mathrm{~m} \text {; } \\
\quad f(t)\end{array}$ \\
\hline $\begin{array}{l}\text { 3.1 What is the sand transport regime in relation to } \\
\text { the current outside the dredged pit (sand ridge)? }\end{array}$ & $\begin{array}{l}\text { Distance from pit to cables, pipelines and offshore } \\
\text { constructions as a function of time }(50-100 \mathrm{yr})\end{array}$ & $\begin{array}{l}\text { Minimum coverage of pipelines }= \\
0.2 \mathrm{~m} \text { or } 40 \% \text { excavation; } f(t)\end{array}$ \\
\hline $\begin{array}{l}\text { 3.2 What is the deformation of the pit (changes in pit } \\
\text { shape, formation of bed patterns, etc.) per year and } \\
\text { over } 50-100 \text { years? What is the influence area? }\end{array}$ & & $\begin{array}{l}\text { Minimum distance to offshore infra- } \\
\text { structure }=500 \mathrm{~m} \text { (with pit } \\
\text { depth of } 2 \mathrm{~m}) ; f(t)\end{array}$ \\
\hline 3.3 What is the migration rate of the pit per year? & & \\
\hline
\end{tabular}

What is the migration rate of the pit per year?

Will the Zeeland ridges recover after they have been
mined away?
If yes:
4.1 Within what period will they recover?

4.2 Will the ridges overshoot the original height? 4.3 Will the recovery affect other nearby sand ridges?

5. Will an offshore extraction pit (mined sand ridge) modify the local flow and wave fields in the area?

5.1 What is the change in maximum tidal current velocity due to the presence of a dredged sand ridge?

5.2 What is the change in wave height during a storm due to the presence of a dredged sand ridge?

6. Will the extraction pit act as sediment sink and thereby have a particularly marked impact on the seabed in the area to the pit?

6.1 What is the change in water depth in the area of the ridges due to the presence of a dredged sand ridge?

6.2 What is the deformation of the pit (changes in pit shape, formation of bed patterns, etc.) per year and over 50-100 years? What is the influence area?

6.3 What is the migration rate of the pit per year?
Navigation

Position ridge(s) as a function of time (50-100 yr)

Not determined yet

Height ridge(s) compared to original height as a function of time (50-100 yr)

Tidal current (magnitude and direction) along nearby shipping channel(s) and at anchor areas as a function of time (short-term and 50-100 yr)

Wave height along nearby shipping channel(s) and at anchor areas as a function of time (short-term and $50-100$ yr)

Water depth in the area of the ridges as a function of time (50-100 yr)

Depth and width of nearby shipping channels as a function of time (50-100 yr)

Distance from pit to nearby shipping channel(s) and anchor areas as a function of time (50-100 yr)
Not determined yet

Minimum change in magnitude and direction; $f(t)$

Minimum change in wave height; $f(t)$

Minimum change in water depth; $f(t)$

Minimum change in depth shipping channel; $f(t)$

Minimum change in width shipping channel; $f(t)$

$f(t)=$ function of time (50-100 years).

* The momentaneous coast line (MCL) is defined as the coastline position with respect to a fixed reference point. It follows from the sand volume underneath a settled beach profile (TAW, 2002).

$\dagger$ "Sand budget in the nearshore zone" is defined as the sand budget per coastal cell from - 20 m NAP until the dune foot (TAW, 2002).

† "Erosion profile" (in Dutch: afslaglijn) is defined as the line that indicates which part of the dune erodes due to a certain storm (TAW, 2002).

March 2000, PUTMOR, an extensive measuring campaign, was held in the Netherlands to collect data about water movement, quality, and morphology in and around a large sand pit (volume $=6.5 \times 10^{6} \mathrm{~m}^{3}$ ) in the North Sea, $10 \mathrm{~km}$ offshore of the Holland coast (northward of the Zeeland ridges). The field data of this PUTMOR project (BoERs, 2005;
SvaSEK, 2001; WALSTRA et al., 2003) were used to evaluate the hydrodynamic performance of Delft3D.

\section{SUTRENCH}

SUTRENCH (SUspended sediment transport in TRENCHes) is a two-dimensional (vertical) morphological model for 


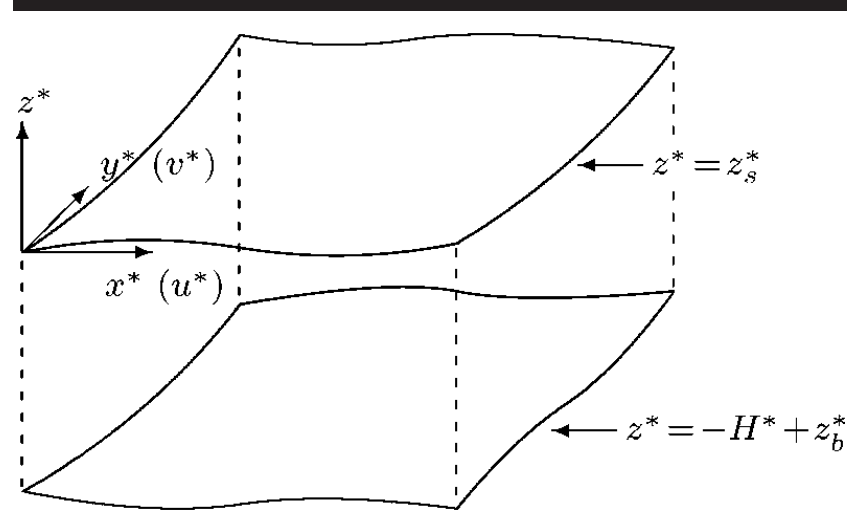

Figure 5. Definition sketch of the model geometry of the Twente model. In this model, a shallow sea of undisturbed depth $H^{*}$ is considered. An orthogonal coordinate system is used, with horizontal coordinates $x^{*}=$ $\left(x^{*}, y^{*}\right)$ and $z^{*}$-axis pointing upward. The free surface is denoted by $z^{*}=$ $z_{\mathrm{s}}^{*}$ and the bed level by $z^{*}=-H^{*}+z_{\mathrm{b}}^{*}$ (Roos and Hulscher, 2003).

the simulation of bed and suspended load transport and the related sedimentation and erosion of dredged channels and trenches. Walstra et al. (1999) used SUTRENCH to model sand transport processes on the lower shoreface (seaward of -20-m depth contour) of the Dutch coast with the aim of predicting the morphological behavior of large-scale sand extraction pits. The performance of SUTRENCH was first eval-

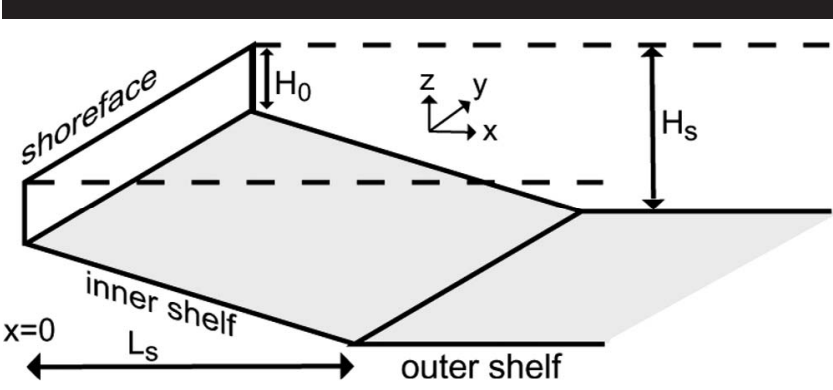

Figure 7. Shelf geometry of the Utrecht model. In this model, the shelf geometry is unrealistic as a semi-infinite domain, bounded on the landward side by the transition from the shoreface to the inner shelf. The reference bathymetry is uniform in the longshore direction $(y)$. In the cross-shore direction $(x)$ it consists of an inner shelf (linearly sloping bottom) and an outer shelf represented by a horizontal bottom. The water depth at the landward side of the inner shelf $(x=0)$ is $H_{0}$, the inner shelf width is $L_{\mathrm{s}}$, and the depth of the outer shelf is indicated by $H_{\mathrm{s}}$. Representative values for the central Dutch coast are $H_{0}=15 \mathrm{~m}, H_{\mathrm{s}}=20 \mathrm{~m}$, and $L_{\mathrm{s}}=12 \mathrm{~km}$ (De Swart and Calvete, 2003).

uated against laboratory data. It was found that the model results corresponded with measurements on this small scale (order of centimeters). Next, a model of the Euro-Maas channel was set up to study the effects of various large-scale sand extraction pits. Using this calibrated model, a prediction of the morphological development of various trench geometries, up to 50 years, was done. According to WALstra et al. (1999),

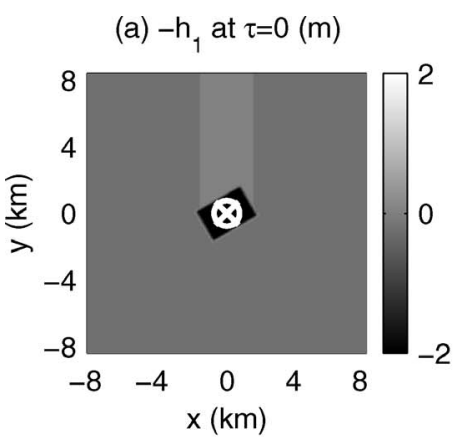

(b) $-h_{1}$ at $\tau=25 \mathrm{yr}(\mathrm{m})$
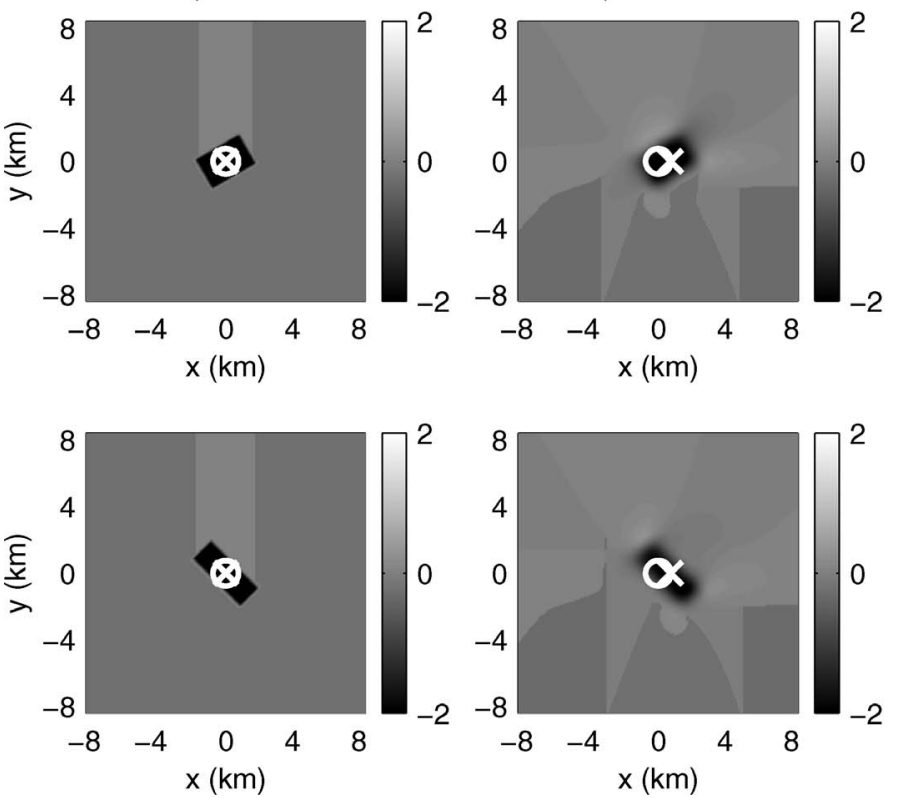

(c) $-h_{1}$ at $\tau=50 \mathrm{yr}(\mathrm{m})$

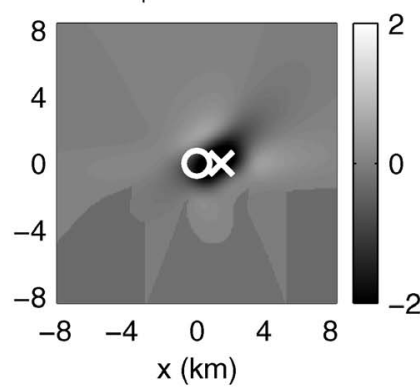

$$
\text { (d) }-\mathrm{h}_{1} \text { at } \tau=100 \mathrm{yr}(\mathrm{m})
$$
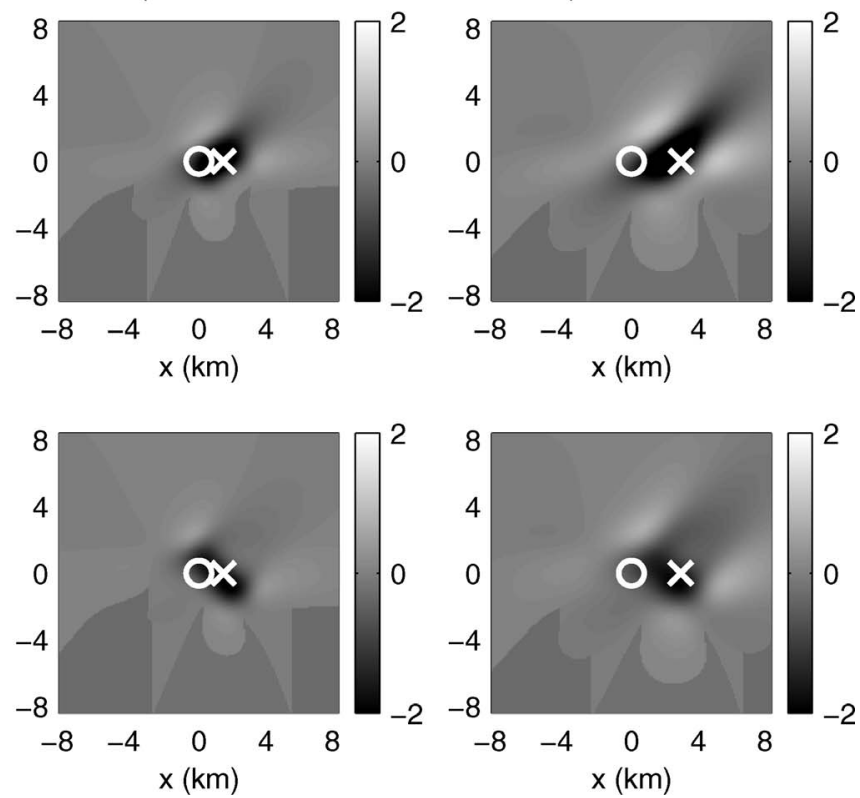

Figure 6. Results of the Twente model. Evolution of two sample pits [12 $\mathrm{Mm}^{3}$, pit depth $\left(h_{\mathrm{pit}}\right)=2 \mathrm{~m}$ and water depth $\left.\left(h_{0}\right)=20 \mathrm{~m}\right]$, subject to asymmetrical tidal flow (tidal current flows from left to right and vice versa, residual current flows from left to right). The tidal conditions are as follows: residual current $\left(M_{0}\right)=0.05 \mathrm{~m} / \mathrm{s}$; amplitude of horizontal $\mathrm{M}_{2}$-tidal velocity $\left(M_{2}\right)=0.95 \mathrm{~m} / \mathrm{s}$ and amplitude of horizontal $\mathrm{M}_{4}$-tidal velocity $\left(M_{4}\right)=0.00 \mathrm{~m} / \mathrm{s}$. Plotted are topographies at (a) $\tau=0$, (b) $\tau=25 \mathrm{yr}$, (c) $\tau=50 \mathrm{yr}$, and (d) $\tau=100 \mathrm{yr}$. The origin is denoted with a circle $\bigcirc$; the pit's center of mass with a cross $\times$. The pit characteristics are top row: pit length $(L)=3 \mathrm{~km}$, pit width $(B)=2 \mathrm{~km}$, pit orientation $(\theta)=30^{\circ}$, bottom row: $L=4 \mathrm{~km}, B=1.5 \mathrm{~km}, \theta=$ $-45^{\circ}$ (Roos, 2004). 

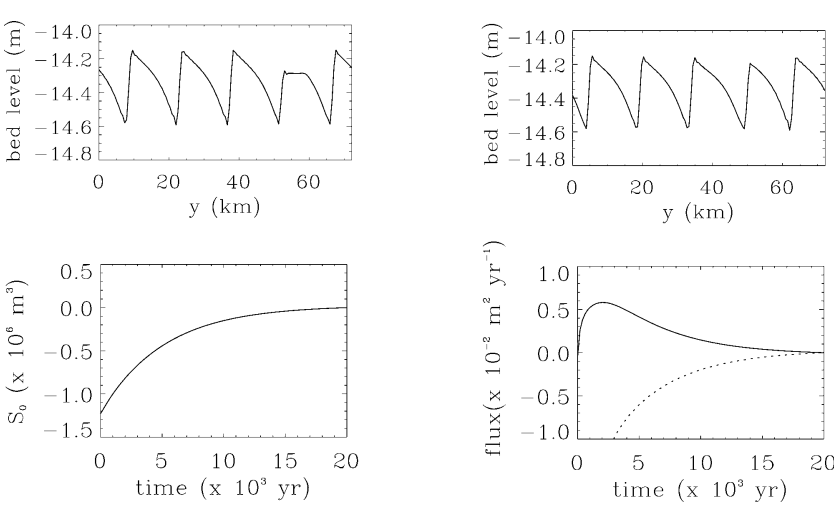

Figure 8. Results of the Utrecht model. Top: Along-shelf transect of the bed level at $x=3 \mathrm{~km}$ (center of the inner shelf), immediately after sand extraction (left) and after 1000 years (right). Bottom; net sand volume $S_{0}$ $\left(\times 10^{6} \mathrm{~m}^{3}\right)$ stored in the inner shelf $v$ s. time (left); net cross-shelf component of the sediment flux $\left(10^{-2} \mathrm{~m}^{2} \mathrm{yr}^{-1}\right)$ induced by the sand extraction at the transition line $x=0$ between inner shelf and nearshore zone (solid line) and at the transition $x=L_{\mathrm{s}}$ between inner and outer shelf (dashed line) (right) (De Swart and Calvete, 2003).

the morphological timescale for the complete filling of a trench (10-14 m depth) is on the order of centuries. However, these are first-order estimates of the morphological timescale (WALstra et al., 1999, WL DelFt Hydraulics, 2003).

\section{Telemac}

The Telemac system (Telemac, 2003) is an integrated modeling tool for use in river and maritime environments. The various simulation modules use algorithms based on the finite-element method. Space is discretized in the form of an unstructured grid of triangular elements, which means that it can be refined particularly in areas of special interest. Telemac consists of several hydrodynamic modules and three transport-dispersion modules (TELEMAC, 2003). IDIER and AsTRUC (2003) showed that the full process-based model is accurate enough to properly simulate the dynamics of the sea bed-free instability waves and, at the same time, to analyze the physical mechanisms of the instability. This is achieved for a steady current over a flat bottom.

\section{mu-SEDIM}

MUMM (Management Unit of the North Sea Mathematical Models, Belgium) developed a two-dimensional total load sediment transport model: mu-SEDIM. The mu-SEDIM model is based on a local total load formula. The bottom stress in this formula is calculated from currents and waves and accounting for the roughness, using a two-dimensional hydrodynamic model (mu-BCZ) and a second-generation wave model (muWAVE). A total load sediment transport formula (ACKERS and WHITE, 1973) is used to calculate the sediment transport vectors. Finally, using the sediment transport calculated at each grid point, the changes in the bed level can be estimated, which highlights the erosion and deposition zones (LANCKNEUs et al., 2001; VAN DEN EYNDE, 2003; MUMM, 2003).

The mu-SEDIM model has been used to model the sedi-

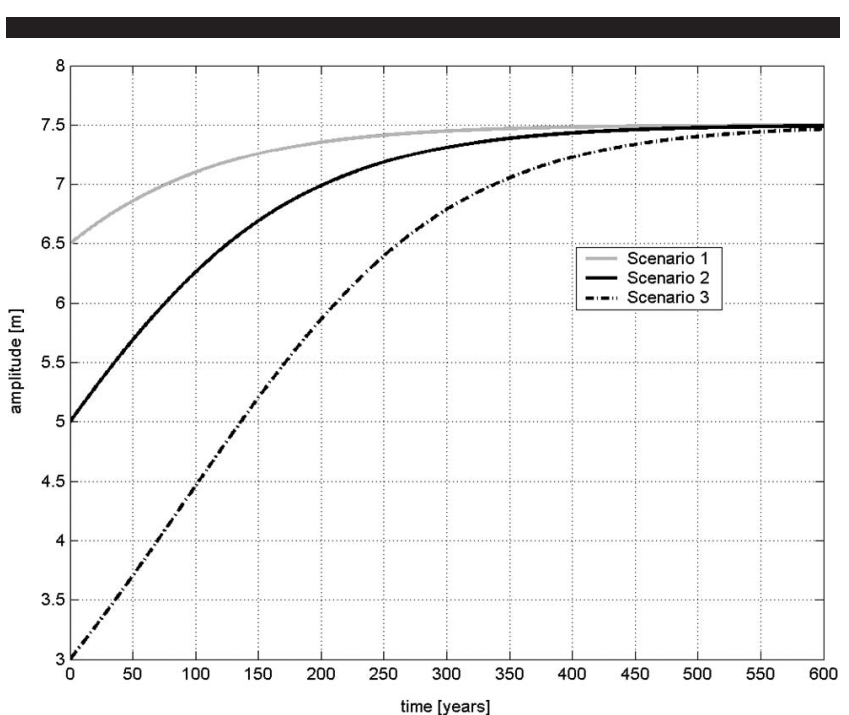

Figure 9. Results of the amplitude-evolution model (Hommes, 2004a). In the model runs, the amplitude before dredging $\left(A_{0}\right)$ is taken at $7.5 \mathrm{~m}$, similar to the amplitude of the Zeeland ridges. The scenarios that are shown in the figure are the following: scenario 1: dredging depth $=2 \mathrm{~m}$; scenario 2: dredging depth $=5 \mathrm{~m}$; scenario 3: dredging depth $=9 \mathrm{~m}$.

ment transport on the Belgian continental shelf (BCS) (LANCKNEUS et al., 2001). Sand extraction (on ridges) has not yet been modeled using mu-SEDIM. However, according to expert judgment, mu-SEDIM could be used to give qualitative insight into the sediment transport in a certain zone after extraction. Note that mu-SEDIM is not a morphological model, but a sedimentation-erosion model; it predicts the initial sedimentation-erosion patterns. Therefore, it would not be suitable for longer-term morphological evolutions of ridges, on the order of hundreds or thousands of years (VAN DE Meene and Van RiJn, 2000). However, because the time scale on which we investigate the morphological development in this study are relatively short (up to 100 years), we assume that the initial response is representative.

\section{Behavior-Oriented Models}

\section{Amplitude-Evolution Model}

KNAAPEN and Hulscher (2002) developed a model to predict the regeneration of sand waves after dredging. Based on the findings of Komarova and Newell (2000), they assumed that the growth of sand waves is described by the Landau equation. However, the Landau equation has been shown to be applicable for several morphologic, rhythmic features (DoDD et al., 2003). Therefore, we adjusted and used the model to predict the regeneration of sand ridges after dredging. The output of the model is the time it takes for a dredged ridge to regenerate to its former (equilibrium) height; this is known as the recovery period. In Figure 9, we investigate the influence of the dredging depth on the recovery period. As would be expected, the recovery period increases with increasing dredging depth. The recovery period of a ridge with a height of $15 \mathrm{~m}$ (amplitude $=1 / 2 \times$ height $=7.5$ 
$\mathrm{m})$, such as the Zeeland ridges, is on the order of hundreds of years.

\section{PREDICTIVE POWER OF MORPHOLOGICAL MODELS}

In this paper, we use the term predictive power to describe how well a model can be used to determine the physical effects of a large-scale sand extraction on a certain CSI. We distinguish two parameters that determine this predictive power: applicability of the model and reliability of the predictions. In the following three sections, these parameters are described. Furthermore, each model is assessed on its predictive power regarding the CSIs of the three coastal user functions: coastal safety and maintenance, offshore infrastructure, and navigation (see "Inventory of Models" section).

\section{Applicability}

Holling (in CostanzA et al., 1993) suggests criteria to evaluate models for their aim and purpose. Realism stands for the capability to describe processes in a system as realistically as possible. Another criterion is generality, which refers to broad applicability. Furthermore, VAN Asselt (2000) describes quality criteria. One group of these is formed by analytical criteria, which concern the credibility of the underlying data sources and theories, the validity of techniques or models used, the level of integration, and the logic of the conclusions. These criteria correspond with the definition of applicability we use in this paper. We define the applicability of a model as the extent to which it provides information that enables us to answer a specific management question and thus a CSI. In this research, we focus on the long term, that is 50-100 years, physical effects. Therefore, only long-term model predictions are taken into account. However, for the CSIs on the change in tidal current and wave height, we also include short-term predictions (see Table 1). We measure the applicability by looking at the mathematical representation of physical processes, which are important to predict the CSIs (second column in Table 2). In this study, the scores for applicability are divided into four categories:

- Not applicable (X): does not represent the physical processes that are important for a certain CSI

- Qualitative (1): qualitative insight into a CSI

- Moderate (2): quantitative insight into a CSI

- Good (3): directly supports the decision-making process

The difference between moderate and good is that moderate results still have to be postprocessed or translated by the modeler into usable information (that is, understandable for decision makers), whereas good results give direct insight to decision makers (for example, a "warning system"). With the models in this paper, it is not yet possible to give decision makers direct insight into the results. Therefore, a kind of user interface or "warning system" still has to be developed in the future for making this possible. Furthermore, a question mark is denoted if we do not know if a model is applicable for use as a CSI. Finally, an $F$ means it will be possible to use the model for a CSI in the near future (within several years). This $F$ is based on discussion with model experts.
Table 2. Physical processes and horizontal spatial scales of the listed CSIs for the reference study area of the Zeeland ridges.

\begin{tabular}{|c|c|c|}
\hline CSI & Physical Processes & $\begin{array}{l}\text { Horizontal Spatial Scale } \\
\text { (order of magnitude) }\end{array}$ \\
\hline \multicolumn{3}{|c|}{ Coastal safety and maintenance } \\
\hline MCL & Sediment transport & $\begin{array}{l}10 \mathrm{~km} \text { (cross-shore dis- } \\
\text { tance ridges to coast) }\end{array}$ \\
\hline $\begin{array}{l}\text { Sand budget in near- } \\
\text { shore zone }\end{array}$ & Sediment transport & $\begin{array}{l}10 \mathrm{~km} \text { (cross-shore dis- } \\
\text { tance ridges to coast) }\end{array}$ \\
\hline Erosion profile & $\begin{array}{l}\text { Wind/storms } \\
\text { Sediment transport }\end{array}$ & $\begin{array}{l}10 \mathrm{~km} \text { (cross-shore dis- } \\
\text { tance ridges to coast) }\end{array}$ \\
\hline \multicolumn{3}{|c|}{ Offshore infrastructure } \\
\hline $\begin{array}{l}\text { Coverage cables and } \\
\text { pipelines }\end{array}$ & Sediment transport & $\begin{array}{l}10 \mathrm{~km} \text { (distance to ca- } \\
\text { bles and pipelines in } \\
\text { the area) }\end{array}$ \\
\hline & Tide & Grid $\pm 100 \mathrm{~m}-2 \mathrm{~km}$ \\
\hline $\begin{array}{l}\text { Distance pit to offshore } \\
\text { infrastructure }\end{array}$ & $\begin{array}{l}\text { Sediment transport } \\
\text { Asymmetrical tide }\end{array}$ & $\begin{array}{l}10 \mathrm{~km} \text { (distance to off- } \\
\text { shore infrastructure } \\
\text { in the area) }\end{array}$ \\
\hline \multicolumn{3}{|c|}{ Navigation } \\
\hline Position ridge(s) & Sediment transport & $\begin{array}{l}10 \mathrm{~km} \text { (transverse } \\
\text { spacing between } \\
\text { ridges) }\end{array}$ \\
\hline & Tide & Grid $\pm 250 \mathrm{~m}-2 \mathrm{~km}$ \\
\hline Height ridge(s) & $\begin{array}{l}\text { Sediment transport } \\
\text { Tide/wind }\end{array}$ & $\begin{array}{l}10 \mathrm{~km} \text { (transverse } \\
\text { spacing between } \\
\text { ridges) }\end{array}$ \\
\hline Tidal current & Tide & $\begin{array}{l}\text { Grid } \pm 250 \mathrm{~m}-2 \mathrm{~km} \\
10 \mathrm{~km} \text { (dimensions of } \\
\text { study area) }\end{array}$ \\
\hline Wave height & Waves & $\begin{array}{l}10 \mathrm{~km} \text { (dimensions of } \\
\text { study area) }\end{array}$ \\
\hline Water depth in area & Sediment transport & $\begin{array}{l}10 \mathrm{~km} \text { (dimensions of } \\
\text { study area) }\end{array}$ \\
\hline $\begin{array}{l}\text { Depth and width ship- } \\
\text { ping channels }\end{array}$ & $\begin{array}{l}\text { Sediment transport } \\
\text { Asymmetrical tide }\end{array}$ & $\begin{array}{l}\text { Grid } \pm 250 \mathrm{~m}-2 \mathrm{~km} \\
10 \mathrm{~km} \text { (distance to } \\
\text { shipping channels) }\end{array}$ \\
\hline $\begin{array}{l}\text { Distance pit to chan- } \\
\text { nels and anchor } \\
\text { areas }\end{array}$ & $\begin{array}{l}\text { Sediment transport } \\
\text { Asymmetrical tide }\end{array}$ & $\begin{array}{l}10 \mathrm{~km} \text { (distance to } \\
\text { channels \& anchor } \\
\text { areas) }\end{array}$ \\
\hline
\end{tabular}

\section{Reliability}

Holling (in Costanza et al., 1993) suggests the criterion precision to indicate a good quantitative correspondence between data and models. Furthermore, VAN Asselt (2000) describes methodological criteria, which address the quality of the methods and approaches adopted, and usability criteria, which involve the degree of relevancy of the assessment for decision making. In this paper, we use the term reliability to show how reliable a prediction is on a CSI with a certain model.

In this study, we measure reliability on two points: the horizontal spatial scale on which the predictions apply and the representation of the physical state. A model scores "realistic spatial scale" when the horizontal spatial scale to which the predictions apply matches with the order of magnitude that is given in Table 2 (third column). Otherwise, it scores "unrealistic spatial scale." Furthermore, a model scores "realistic physical state" when the area is described using real data or values, for instance on the following parameters: bathymetry (nonflat bottom), pit depth, bottom 


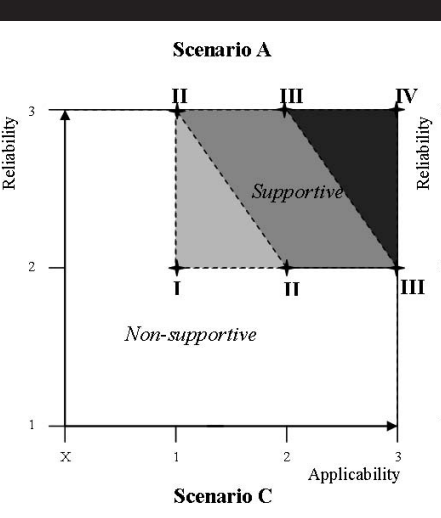

Scenario B
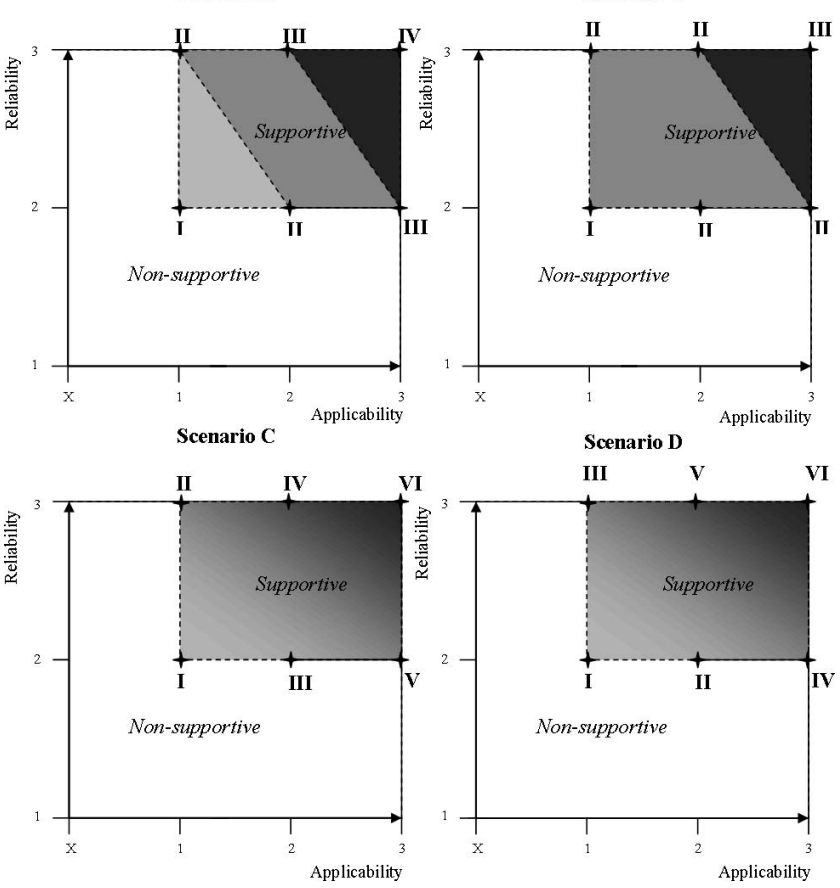

Figure 10. Definition predictive power models. The axes represent the following parameters. Applicability ( $x$-axis): $\mathrm{X}=$ not applicable; $1=$ qualitative; 2 = quantitative; $3=$ direct support. Reliability $(y$-axis): $1=$ unrealistic spatial scale, unrealistic physical state; $2=$ realistic spatial scale, unrealistic state; $3=$ realistic spatial scale, realistic state. The colors have the following meaning: white indicates that a model does not support decision-making on a certain CSI; from light-gray, middle-gray to dark-gray the amount of support of a model on a CSI increases. The following four scenarios are defined: scenario $\mathrm{A}=$ predictive power score $\mathrm{I}-\mathrm{IV}$; scenario $\mathrm{B}=$ predictive power score $\mathrm{I}-\mathrm{III}$; scenario $\mathrm{C}=$ predictive power score I-VI, applicability more important than reliability; scenario $\mathrm{D}=$ predictive power score I-VI, reliability more important than applicability.

slope. Otherwise, it scores "unrealistic physical state." Finally, these two parameters together determine the scores on reliability. The scores for reliability are divided into three categories:

- Not reliable (1): The model represents the physical processes, on an unrealistic spatial scale (which has to be extrapolated, for example: too small spatial scale) and with an unrealistic physical state (for example, flat sea bottom).

- Moderate (2): The model represents the physical processes on a realistic spatial scale, with an unrealistic physical state.

- Good (3): The model represents the physical processes on a realistic spatial scale and in a realistic physical state.

Note that if a model is assessed with an $F$, not applicable, or a question mark to a CSI, clearly no score on reliability can yet be given. All scores for applicability and reliability are based on in-depth interviews with model experts and the results from the workshop with model experts (see Hommes, 2004b)
Table 3. Predictive power of models on the CSIs and highest scores on each CSI. The scores on applicability and reliability are defined as follows: $A=$ applicability $; X=$ not applicable; does not represent physical processes (white), 1 = qualitative; qualitative insight (light gray), 2 = moderate, quanitative insight (medium gray), 3 = good; direct support decision-making process (dark gray), ? = no experience (white), $F=$ possible to apply in near future (white).

$R=$ reliability $; X=$ not applicable (white), $1=$ not reliable; represents physical processes on unrealistic spatial scale with unrealistic physical state (light gray), 2 = moderate; represents physical processes on realistic spatial scale with physical unrealistic state (medium gray), $3=$ good; represents physical processes with realistic physical state (dark gray); ? = no experience (white); $F=$ possible in near future (white).

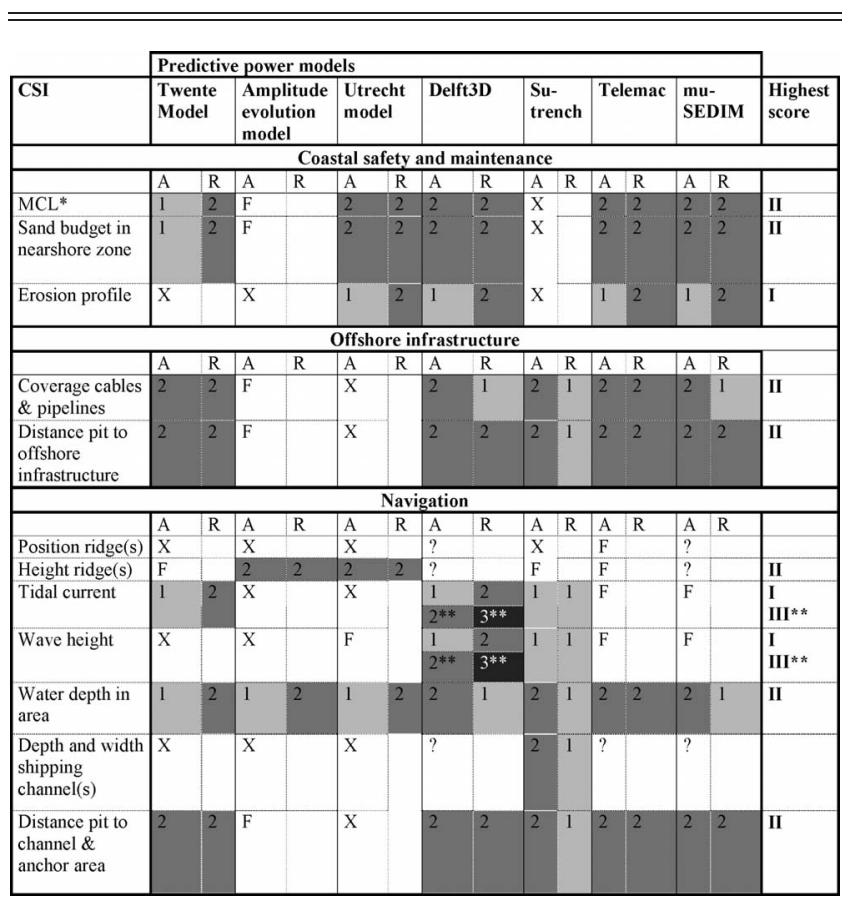

* Momentaneous coast line.

*** For short-term predictions.

\section{Predictive Power}

In Figure 10, the predictive power of a model is defined. This predictive power can be split up into nonsupportive and supportive with regard to the decision-making process. Furthermore, we assume that the applicability of a model is equally important as the reliability of a prediction (Scenario A). Therefore, a "quantitative prediction on a realistic spatial scale and an unrealistic physical state" scores the same as a "qualitative prediction on a realistic spatial scale and physical state." Moreover, we assume two levels between the lowest and the highest predictive power.

\section{Inventory of Models}

An overview of the predictive power of the selected models, for each CSI, is given in Table 3. The full process-based mod- 


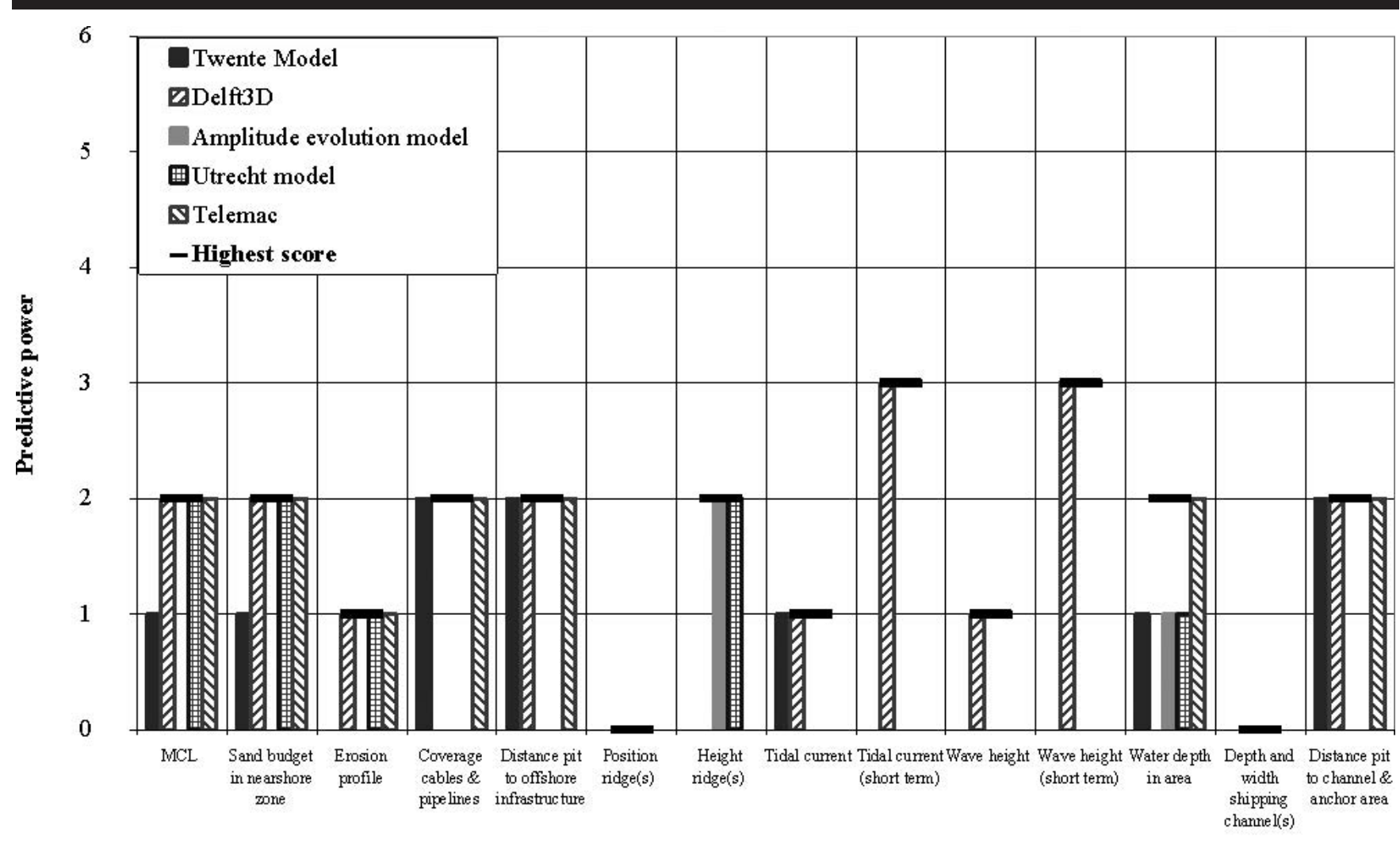

Coastal State Indicator (CSI)

Figure 11. Predictive power models on the CSIs and highest scores on each CSI of the coastal user functions: coastal safety and maintenance; offshore infrastructure; and navigation.

els Delft3D, Telemac, and mu-SEDIM ${ }^{1}$ and the idealized-process based Utrecht model turn out to be most applicable to the CSIs of coastal safety and maintenance. However, we must be aware that predictions over long timescales (50-100 years) require large computational times when using full process-based models. Therefore, the Twente model is, and in the near future the amplitude-evolution model will be, promising in terms of achieving fast qualitative insight.

Based on the model possibilities and the interviews and workshop with model experts, we can assume that Delft3D, Telemac, and mu-SEDIM are capable of giving quantitative insight into an unrealistic state for the CSIs on offshore infrastructure, although no calculations of this kind have yet been done using these models. However, here also we are dealing with large computational times for predictions over longer timescales. Furthermore, the Twente model can give reliable quantitative insight into the effects of large-scale sand extraction on offshore infrastructure with an unrealistic state and the amplitude-evolution model could be used for these CSIs in the near future as well.

${ }^{1}$ The predictive power of mu-SEDIM is not corrected for the fact that it is not a morphological model, but a sedimentation-erosion model. Keep in mind, however, that this model is not suitable for longer-term morphological evolutions of ridges, on the order of hundreds or thousands of years.
The first CSIs for navigation focus on the recovery of the Zeeland ridges after extraction. Only the amplitude-evolution model and Utrecht model are capable of predicting the recovery of ridge heights after extraction. The Twente, SUTRENCH, and Telemac models could be applied for the CSI "height ridge(s)" in the near future. There is a lack of experience using Delft3D and mu-SEDIM on this point. For the CSIs, on the hydrodynamic effects of sand extraction Delft3D and, in the near future Telemac and mu-SEDIM, give reliable results, but only on short-term predictions. For the long-term predictions, Delft3D and the Twente model can give qualitative insight. The Utrecht model could be extended to predict the influence of a large-scale extraction on the wave height in the area. The last CSIs focus on the morphological effects of sand extraction. All models can be applied to predict the changes in water depth in the area after extraction. However, currently there is no model that can be used to predict the influence of a pit on the depth and width of adjacent shipping channels. Finally, to predict the changing distance from the pit to shipping channel(s) and/or anchor areas, the Twente, Delft3D, SUTRENCH, Telemac, and mu-SEDIM models are capable of giving quantitative insight into an unrealistic state.

In Figure 11, the predictive power of each model for each CSI is given. Furthermore, the highest score on each CSI is 
Table 4. Sensitivity analysis of the definition of the term predictive power.

\begin{tabular}{lrrrrrr}
\hline \hline \multicolumn{1}{c}{ Scenario } & A & B & C & D & E & F \\
\hline Twente model & 10 & 10 & 10 & 10 & 10 & 14 \\
Amplitude-evolution model & 3 & 3 & 3 & 3 & 3 & 4 \\
Utrecht model & 8 & 8 & 8 & 8 & 8 & 10 \\
Delft3D & 17 & 15 & 21 & 21 & 21 & 22 \\
Sutrench & 0 & 0 & 0 & 0 & 12 & 7 \\
Telemac & 13 & 13 & 13 & 13 & 13 & 14 \\
mu-SEDIM & 9 & 9 & 9 & 9 & 13 & 12 \\
Highest score (parallel mod- & & & & & & \\
$\quad$ eling approach) & 23 & 21 & 27 & 27 & 23 & 27 \\
Minimal set of models & 3 & 3 & 3 & 3 & 3 & 4 \\
Increase predictive power & $35 \%$ & $40 \%$ & $29 \%$ & $29 \%$ & $10 \%$ & $23 \%$ \\
\hline
\end{tabular}

In this analysis, the following scenarios are tested (see also Figure 8): Scenario A = predictive power score I-IV. Scenario B = predictive power score I-III. Scenario C = predictive power score I-VI, applicability more important than reliability. Scenario $\mathrm{D}=$ predictive power score I-VI, reliability more important than applicability. Scenario $\mathrm{E}=$ only assess on applicability. Scenario F = only assess on reliability.

shown by black lines (also given in last column of Table 3). From this figure, we can conclude that the highest scores are not achieved by the same model for every management question (CSI). We find that the overall highest scores for the questions are achieved by using a set of models parallel to each other. In Table 4 (scenario A), the sum of total scores on predictive power are given for each model separately and for sets of models leading to the highest scores. The latter is calculated using the following formula:

$$
\text { Total_PP }=\sum_{n=1}^{N} \operatorname{Max} \operatorname{PP}(n)
$$

in which $\mathrm{PP}=$ predictive power of a model and $N=$ total number of CSIs, here 14.

From the highest score (TotalPP) we can determine what we might gain when using a parallel modeling approach to answer several management questions (CSIs). The model that scores best has a total score of 17 , whereas the total highest score is 23 . This shows that we gain significantly, that is $35 \%$, on predictive power by using a parallel modeling approach instead of using the single best model. Furthermore, we find that to reach the highest score of 23 , the minimal set of models is three.

\section{SENSITIVITY ANALYSIS}

\section{Sensitivity to Predictive Power Scores}

Scenarios B to D (Table 4) show the sensitivity of the definition of predictive power. In scenario B (Figure 10), we defined only three scores for predictive power, so only one level between the lowest and the highest predictive power. Scenarios $\mathrm{C}$ and D (Figure 10) give the scores on predictive power with six levels instead of four. When using one of these scenarios, one has to define which parameter is more important: applicability or reliability.

Although the scores change with different scenarios, the total highest score of the set of models is still higher than the highest score of the single models. The increase in predictive power for scenario B is even a little higher than before: $40 \%$ instead of $35 \%$. For scenarios $\mathrm{C}$ and $\mathrm{D}$, the increase in predictive power is a little lower, 29\%. Furthermore, for these scenarios we also need a set containing a minimum of three models.

\section{Sensitivity to Applicability and Reliability}

In scenarios $\mathrm{E}$ and $\mathrm{F}$ (Table 4), we tested the results on the sensitivity to the use of the parameters of applicability and reliability. Scenario E shows the results when only the applicability of the models is taken into account. The increase in predictive power for this scenario is only 10\%. For this scenario we also need a set containing a minimum of three models. Scenario F, on the other hand, only takes the reliability of the model predictions into account; the increase in predictive power for this scenario is $23 \%$. However, now we need a set containing a minimum of four models. We can see that the results of these two scenarios differ enormously for some models in comparison with scenario A. However, here the total highest score of the parallel modeling approach remains higher than the highest score of one of the models.

\section{DISCUSSION}

\section{Complex Management Issue}

In this study, we are dealing with a complex problem because we face a problem that involves a lot of different stakeholders (for example: fishery, navigation, government, recreational sector, offshore sector). These stakeholders all have their own objectives. Furthermore, there are a lot of uncertainties occurring, for example, in model predictions. In this paper, we present a parallel modeling approach to answer as many management questions, focusing on morphological impacts of sand extraction, as possible at this moment using existing morphological models. To illustrate this approach, we use a reference study area, the Zeeland ridges, and a certain set of morphological models. Although, this is a unique case and set of models, we argue that applying the approach to another area or using another set of morphological models would not have changed our results. That is, the predictive power of a set of models used parallel to each other would still be larger than that of a single best model. However, when we would be dealing with a simple problem, it could be possible that we only need to answer a single management question or a small set of them. In such a case, it is probably sufficient to use just one single model instead of several models parallel to each other. Furthermore, alternatives to the parallel modeling approach that give an equal amount of information could be an adaptation of a model or the development of a new model. These options usually take quite some time and have several risks. This means that running several existing models parallel to each other is an attractive alternative if fast answers are needed for decision making.

\section{Morphological Models}

A difficult point in the field of morphology is the lack of measurement data on morphological impacts of large-scale sand extraction. This makes it currently impossible to vali- 
date the morphological models presented in this paper. Furthermore, we must note that social and political processes, in the end, determine whether new knowledge, as in this case from model predictions, will play any role in the decisionmaking process (PETERs and Hulscher, 2006). However, if field measurements on morphological impacts would be available, the Brier Skill Score method by SutherLAnd, PeEt, and Soulsby (2004) is a useful method to determine the performance of different models in a quantitative way. Whereas if field measurements are not available and thus validated morphological models are not available, as in most large-scale sand extraction cases, the qualitative predictive power method as presented in this paper can be used.

The authors realize that not all models that were selected are the most suitable model for this case, e.g., the Zeeland ridges have a certain orientation to the main tidal axis and SUTRENCH is a two-dimensional vertical model. This makes it difficult to choose the direction of the vertical plane. However, we did include the models presented here as: (1) they have been put forward by model experts as potential models and (2) if a model is not performing well, this should also be the result (in predictive power), so this gives an internal validation check. Furthermore, it is also possible to perform model-to-model validation when several models answer the same management question.

In the "Inventory of Models" section, computer time requirements are named as a disadvantage of full processbased models. One should realize, however, that many of these model systems remain to make optimum use of the possibilities of high-power computing, while computer power as such keeps on increasing rapidly. Furthermore, in estimating the predictive power of the different models, the authors leave the modeler's skill out of consideration. However, one should keep in mind that it is the "man-machine" combination that in the end determines the quality of a model application. Finally, all models that are investigated in this paper assume infinite sediment availability. For the case of the Zeeland ridges this is permitted because sediment availability is not an issue in this part of the North Sea. However, in other areas throughout the world, sediment availability can be limited so this should be taken into account.

\section{Classification of Zeeland Ridges}

As stated before, no clear conclusion can be drawn on the classification of the Zeeland ridges. They have characteristics of both tidal sand ridges and shoreface-connected ridges. This indistinctness hinders a starting point for predicting the future effects of extraction in this area because some models are specially developed for certain features. Therefore, we use idealized process-based models for both tidal sand ridges (Twente model) and shoreface-connected ridges (Utrecht model), supposing that they all incorporate the representative physical mechanisms. However, if the kind of features we are dealing with would have been clear, using models for both types of ridges would have been unnecessary.

\section{Method for License Applicants}

We used the approach as shown in Figure 1. This proved to be a useful tool for investigating the information needs (management questions) of coastal managers; formulating research questions, CSIs, and assessment criteria in cooperation with model experts; and determining a set of morphological models that can be used to predict the physical effects of a large-scale offshore sand extraction. Therefore, we claim that it could also be useful for organizations that are planning to execute a large-scale sand extraction and thus have to apply for a license. In this section, we describe the six phases of the approach in more detail.

\section{Phase 1: Exploration Management Questions}

In the first phase the management questions are explored by interviews with decision makers. Furthermore, the initiator of the large-scale sand extraction should determine the basic assumptions, e.g., temporal and spatial scale, for the research that has to be done to predict the effects of the extraction. These basic assumptions are (partly) based on regulations, like RON2 (Rijkswaterstaat, 2004) in the Netherlands. Moreover, a list of information users should be formulated in the first phase. The information users are involved either because they will possibly be affected by the extraction (e.g., environmental organizations, fishery, sand market) or because they have an influence on the outcome (e.g., decision makers). Finally, a process information chain is constructed to determine who undertakes what activities to achieve certain management goals and what information is needed to realize these goals (see Figure 2).

\section{Phase 2: Adjustment}

The second phase is the adjustment phase. In this phase, basic information needs (outcome from the exploration phase) are discussed and adjusted with the cooperation of experts in the field. This can be done by organizing a meeting or workshop. The outcome of this phase is a set of management questions.

\section{Phase 3: Current Situation and Morphological Models}

It is important to know the current situation before one can predict the influence of sand extraction. Therefore, the initiator should investigate, for instance, the geomorphology, origin, sediments, and physical processes in the area where the sand extraction is planned. Furthermore, the information needs of the different stakeholders in the process can be analyzed using interviews, information from previous research, workshops, and literature. Furthermore, CSIs are used to express information needs in quantifiable parameters. Finally, the initiator should select different models, with the help of experts in the field, to include the concept inventory of models. Then the current possibilities and limitations of these models are explored.

\section{Phase 4: Assessment of Predictive Power}

This phase can be accomplished with the organization of a workshop for model experts. At this workshop the participants can be asked to give a presentation on their model. 
After these presentations, a discussion could be held regarding modeling of the effects of the proposed sand extraction.

\section{Phase 5: Select and Run Models}

The result of phase 4 is an inventory of models that can be used to predict the physical effects of the proposed large-scale sand extraction. In this inventory the predictive power is indicated for the different models. This parameter shows the initiator which models are applicable to which CSIs and with what reliability. The next step is then to choose and run a set of models, parallel to each other.

\section{Phase 6: Answer Management Questions}

In the last phase of the approach the different models' predictions are used to answer the CSIs and thus the management questions. The outcomes of this phase are used to apply for a sand extraction license.

\section{CONCLUSIONS}

In this paper, we focus on a complex management issue, namely the physical effects of a large-scale offshore sand extraction. For these kinds of issues there is no obvious morphological model available to answer all management questions. Therefore, we aim to answer as many management questions as possible using a set of existing morphological models parallel to each other. In this way, we can support the decision-making process on granting licenses for largescale sand extraction. In this paper, we investigated the Zeeland ridges, a group of sand ridges offshore of the Netherlands. Although we use a Dutch case as a reference study area, the method presented in this paper can also be applied to other areas throughout the world where similar issues are at stake (e.g., United States, United Kingdom, Japan). The management questions for the area of the Zeeland ridges are translated into quantifiable parameters, known as CSIs, in cooperation with decision makers and model experts. And the morphological models are assessed on their applicability to the CSIs and the reliability of their predictions. In this paper, we calculate the predictive power based on these two parameters.

The predictive power of the models showed that by using a parallel modeling approach, it is possible to answer more management questions effectively, in comparison with using just the best model of this set. The increase of the predictive power is significant, at $35 \%$, and we need a minimal set of three models to reach this value. We test the sensitivity of both the results and the assessment method by changing the definition of the predictive power (other score levels; assess only on applicability or only on reliability). This sensitivity analysis showed that the scores of the parallel modeling approach (highest scores) is always higher than the scores of a single model in every scenario.

One of the strengths of the assessment method presented in this paper is that it measures two parameters, namely applicability and reliability. Furthermore, the results show us that although we are not yet capable of answering all management questions, we can give qualitative and quantitative insight into most CSIs by using a parallel modeling approach. We conclude that in the case of a complex management issue like large-scale offshore sand extraction, one finds significantly more information on the long-term physical effects by using a parallel modeling approach than by using just the best single model.

\section{ACKNOWLEDGMENTS}

The research was accomplished at the National Institute of Coastal and Marine Science (RIKZ); the authors are grateful for this opportunity. The research is linked to the Ph.D. research of S. Hommes, which is embedded in the VICI-project "Rough Water." Furthermore, we are grateful for the help of Marien Boers (RIKZ) and Jan Mulder (RIKZ) on the formulation of the research questions and CSIs.

\section{LITERATURE CITED}

ACKeRs, P. and White, W.R., 1973. Sediment transport: new approach and analysis. Proceedings of the ASCE Journal of Hydraulics Division, 99, HY11, 2041-2060.

Boers, M., 2005. Effects of a Deep Sand Extraction Pit. Final report of the PUTMOR measurements at the lowered dump site. The Hague, The Netherlands: Rijksinstituut voor Kust en Zee/RIKZ, RIKZ/2005.001 (ISBN 90-369-3498-2). 87p.

Byrnes, M.R.; Hammert, R.M.; Thibaut, T.D., and SNyder, D.B., 2004a. Physical and biological effects of sand mining offshore Alabama, USA. Journal of Coastal Research, 20(1), 6-24.

Byrnes, M.R.; HAmmert, R.M.; Thibaut, T.D., and Snyder, D.B., 2004b. Effects of sand mining on physical processes and biological communities offshore New Jersey, USA. Journal of Coastal Research, 20(1), 25-43.

Costanza, R.; Wainger, L.; Folke, C., and Mäler, K.-G., 1993. Modeling complex ecological economic systems. Bioscience, 43(8), $545-555$.

De Swart, H.E. and Calvete, D., 2003. Non-linear response of shoreface-connected sand ridges to interventions. Ocean Dynamics, 53, 270-277.

Dewicke, A.; Cattrijsse, A.; Mees, J., and VincX, M., 2003. Spatial patterns of the hyperbenthos of subtidal sandbanks in the southern North Sea. Journal of Sea Research, 49(1), 27-45.

Dodd, N.; Blondeaux, P.; Calvete, D.; De Swart, H.E.; FALQUÆEes, A.; Hulscher, S.J.M.H.; RóżYŃSKI, G., and VITTORI, G., 2003. Understanding coastal morphodynamics using stability methods. Journal of Coastal Research, 19(4), 849-865.

Drucker, B.S.; Waskes, W., and BYrNES, M.R., 2004. The US minerals management service outer continental shelf sand and gravel program: environmental studies to assess the potential effects of offshore dredging operations in federal waters. Journal of Coastal Research, 20(1), 1-5.

Het GETIJ, 2005. www.getij.nl (accessed October 1, 2005).

Hilton, M.J. and Hesp, P., 1996. Determining the limits of beachnearshore sand systems and the impact of offshore coastal sand mining. Journal of Coastal Research, 12(2), 496-519.

HitchCOCK, D.R. and BeLL, S., 2004. Physical impacts of marine aggregate dredging on seabed resources in coastal deposits. Journal of Coastal Research, 20(1), 101-114.

Hommes, S., 2004a. Large-Scale Sand Extraction on Sand Ridges Offshore of the Netherlands-Inventory of Instruments to Predict Physical Effects of Sand Extraction on the Zeeland Ridges. Enschede, the Netherlands: University of Twente. CE\&M research report 2004R-003/WEM-006, ISSN 1568-4652. 151p. Available online: http://www.wem.ctw.utwente.nl/organisatie/Medewerkers/ medewerkers/hommes/Saskia\%20Hommes/ (accessed January 1, 2006).

Hommes, S., 2004b. Workshop: Modelling Sand Mining on the Zeeland Ridges (November 18, 2003). The Hague, The Netherlands: Rijksinstituut voor Kust en Zee/RIKZ, 48p. Available online: 
http://www.wem.ctw.utwente.nl/organisatie/Medewerkers/ medewerkers/hommes/Saskia\%20Hommes/ (accessed January 1, 2006)

Hoogewoning, S.E. and Boers, M., 2001. Fysische effecten van zeezandwinning (Physical effects of sea sand extraction). The Hague, The Netherlands: Rijksinstituut voor Kust en Zee/RIKZ, RIKZ/2001.050. 95p. (in Dutch).

IDIER, D. and AstruC, D., 2003. Analytical and numerical modeling of sandbanks dynamics. Journal of Geophyshysical Research, 108(C3), 3060

Kelley, S.W.; RAmsey, J.S., and Byrnes, M.R., 2004. Evaluating shoreline response to offshore sand mining for beach nourishment. Journal of Coastal Research, 20(1), 89-100.

Kleinhans, M.G., 2002. Sediment Dynamics on the Shoreface and Upper Continental Shelf, a Review. The Netherlands: Utrecht University, Physical Geography, Sandpit, EC MAST Project No. MAS3-CT97-0086. 68p.

KNAAPEN, M.A.F. and Hulscher, S.J.M.H., 2002. Regeneration of sand waves after dredging. Coastal Engineering, 46, 277-289.

Komarova, N.L. and Newell, A.C., 2000. Nonlinear dynamics of sandbanks and sand waves. Journal of Fluid Mechanics, 415, 285321.

Lanckneus, J.; Van Lancker, V.; Moerkerke, G.; Van Den EynDE, D.; Fettweis, M.; De Batist, M., and Jacobs, P., 2001. Investigation of the Natural Sand Transport on the Belgian Continental Shelf (BUDGET). Brussels: Federal Office for Scientific, Technical and Cultural Affairs (OSTC), 104p. + 87p. Annex.

MAA, J.P.Y.; HobBs, C.H.; KIM, S.C., and WeI, E., 2004. Potential impacts of sand mining offshore of Maryland and Delaware: Part I-Impacts on physical oceanographic processes. Journal of Coastal Research, 20(1), 44-60.

MUMM, 2003. www.mumm.ac.be (accessed December 1, 2003).

NoORDZEEATlas, 2005. www.noordzeeatlas.nl (accessed October 1, 2005).

Pattiaratchi, C.B. and Harris, P.T., 2002. Hydrodynamics and sand-transport controls on en echelon sandbank formation: an example from Moreton Bay, eastern Australia. Marine and Freshwater Research, 53, 1101-1113.

Peters, B.G.T.M. and HuLscheR, S.J.M.H., 2006. Large-scale offshore sand extraction: what could be the results of interaction between model and decision process? Ocean \& Coastal Management, 49(3-4), 164-187.

RiJKSWATERSTAAT, 2004. Regionaal Ontgrondingenplan Noordzee 2 (RON2). The Netherlands: Directie Noordzee, 83p. (in Dutch).

Roos, P.C., 2004. Seabed Pattern Dynamics and Offshore Sand Extraction. Enschede, The Netherlands: University of Twente, Doctoral thesis, ISBN 90-365-2067-3, 167p.

Roos, P.C. and Hulscher, S.J.M.H., 2003. Large-scale seabed dynamics in offshore morphology: modeling human intervention. Review of Geophysics, 41(2), 1010.

Roos, P.C.; Hulscher, S.J.M.H.; Peters, B.G.T.M., and Németh, A.A., 2001. A simple morphodynamic model for sandbanks and large-scale sand pits subject to asymmetrical tides. In: IKEDA, S. (ed). Proceedings RCEM Symposium 2001, IAHR. Hokkaido, Japan: Hokkaido Univeristy Press, pp. 91-100.

Singleton, G.H., 2001. Marine aggregate dredging in the UK: a review. Underwater Technology, 25(1), 3-13.

STOLK, A., 2003. Regelgeving en milieuaspecten bij de winning van mineralen in de Noordzee. Congress syllabus 4e Nationaal Slibcongres-Schijn bedriegt. 23 October 2003, Amersfoort, Stichting Klasse 4, Leusden, The Netherlands (in Dutch).

Sutherland, J.; Peet, A.H., and Soulsby, R.L., 2004. Evaluating the performance of morphological models. Coastal Engineering, 51, 917-939.

SvASEK, 2001. PUTMOR, Field Measurements at a Temporary Sand Pit. Part 3: Final Report. The Netherlands: Svasek Coastal \& Har- bour Engineering Consultants. Prepared for: the National Institute for Coastal and Marine Management (RIKZ) and the Directorate North Sea (DNZ) of the Directorate-General for Public Works and Water Management (RWS), Report 01453/1177. 27p.

TAw, 2002. Leidraad Zandige Kust, Den Haag, The Netherlands: Technische Adviescommissie voor de Waterkeringen, ISBN: 90369-5541-6, 224p (in Dutch).

Telemac, 2003. http://www.telemacsystem.com (accessed December $1,2003)$.

TsURUSAKI, K.; IwASAKI, T., and ARITA, M., 1988. Seabed sand mining in Japan. Marine Mining, 7(1), 49-67.

VAN Asselt, M.B.A., 2000. Perspectives on Uncertainty and RiskThe PRIMA Approach to Decision Support. The Netherlands: University of Maastricht. Doctoral thesis, ISBN: 0-7923-6656-5, 434p.

Vanaverbeke, J.; Gheskiere, T.; Steyaert, M., and VincX, M., 2002. Nematode assemblages from subtidal sandbanks in the Southern Bight of the North Sea: effect of small sedimentological differences. Journal of Sea Research, 48(3), 197-207.

VAn De MeEne, J.W.H., 1994. The shoreface-connected ridges along the central Dutch coast. University of Utrecht, Netherlands. Doctoral thesis, ISBN 90-6266-112-2, 222p.

Van De Meene, J.W.H. and Van RIJn, L.C., 2000. The shorefaceconnected ridges along the Dutch coast-part 2: morphological modelling. Continental Shelf Research, 20, 2325-2345.

VAN Den Eynde, D., 2003. Het numerieke model mu-SEDIM voor de bepaling van het totale sedimenttransport in de Belgische Kustwateren. Brussel: Beheerseenheid van het Mathematische Model Noordzee (BMM), MOMO/1/DVDE/200309/NL/TR/1. 22p. (in Dutch).

Van Koningsveld, M.; Davidson, M.A., and Huntley, D.A., 2005. Matching science with coastal management needs; the search for appropriate coastal state indicators. Journal of Coastal Research, 21(3), 399-441.

Van RiJn, L.C.; Soulsby, R.L.; Hoekstra, P., and Davies, A.G., 2005. SANDPIT: Sand Transport and Morphology of Offshore Mining Pits-Process Knowledge and Guidelines for Coastal Management, The Netherlands: Aqua Publications, ISBN 90-800356-7-X, EC Framework V Project No. EVK3-2001-00056, 151p.

VAN RIJN, L.C. and WALSTRA, D.J.R., 2002. Morphology of Pits, Channels and Trenches. Part I. Literature Review and Study Approach. The Netherlands: WL Delft Hydraulics. Prepared for: DG Rijkswaterstaat, Rijksinstituut voor Kust en Zee-RIKZ, Z3223. $92 \mathrm{p}$.

Van Woerden, J.A., 2002. Syntheserapport Grootschalig Diep Zandwinnen. Delft, The Netherlands: TNO-TPD, prepared for: Rijkswaterstaat, Directie Noordzee, TNO-report DIS-RTP-010127. $27 \mathrm{p}$ (in Dutch).

Vincent, C.E.; Stolk, A., and Porter, C.F.C., 1998. Sand suspension and transport on the Middelkerke Bank (southern North Sea) by storms and tidal currents. Marine Geology, 150, 113-129.

Walgreen, M., Calvete, D., and De Swart, H.E., 2002. Growth of large-scale bed forms due to storm-driven and tidal currents: a model approach. Continental Shelf Research, 22, 2777-2793.

WAlstra, D.J.R.; VAN RiJn, L.C.; BoERs, M., and RoElvinK, J.A., 2003. Offshore sand pits: verification and application of hydrodynamic and morphodynamic models. In: International Conference on Coastal Sediments 2003. Florida.

Walstra, D.J.R.; VAN RIJn, L.C.; Hoogewoning, S.E., and AarNINKHOF, S.G.J., 1999. Morphodynamic modelling of dredged trenches and channels. In: International Conference on Coastal Sediments 1999.

WL Delft Hydraulics, 2003. www.wldelft.n (accessed October 1, 2003).

Yoshida, M. and TAKasugi, Y., 2005. Influence of artificial topographical transformation on the tide in the Seto Inland Sea, Japan. Journal of Waterway Port Coastal and Ocean EngineeringASCE, 131(2), 62-68. 